\title{
The impact of training on the improvement of skills of manufacturing skilled workers in the context of big data and legal consideration
}

\author{
XU Hongfei ${ }^{1}$ \\ ${ }^{1}$ Department of Law, School of Law, Humanties and Sociology, WUT, WuHan, HuBei, China
}

\begin{abstract}
With the key words of skilled worker training, evaluation, innovation, mobility and motivation, three sets of relevant survey questionnaires were designed for skilled workers, managers and enterprises, and they were used in more than ten enterprises in Hubei. In the questionnaire data statistics, according to the principle of "single-question compliance", data that does not meet the requirements of the topic selection is eliminated. Based on high-quality development and manufacturing in Hubei Province, this article summarizes and puts forward the problems that exist in the training process and the improvement of skills of manufacturing skilled workers in Hubei Province under the background of big data through the analysis of effective data and field investigations. Thinking about the corresponding countermeasures from the legal level.
\end{abstract}

\section{Understanding the problem of improving the quality of manufacturing skilled workers under the background of big data}

On September 4, 2008, the US "Nature" magazine first proposed the concept of "big data". Through the extensive absorption, collection, processing, calculation, and induction of data, some hidden data can be exposed. Of course, the value of big data must not be ignored in the development of law, and great convenience must also be seized to scientifically summarize social issues.

Industrial workers are the main force supporting the working class, and technical workers with certain technical capabilities among industrial workers are an important factor in promoting industrial technology upgrading. In February 2017, the Central Committee of the Communist Party of China and the State Council issued the "Industrial Worker Team Building Reform Plan in the New Era"[1] which clarified the importance of industrial workers, and the importance of skilled workers as the backbone of industrial workers is even more selfevident. Therefore, it is particularly important for manufacturing enterprises to improve the skills of skilled workers through training.Faced with the new and complex situation, skilled workers may lose their jobs at any time if they do not pay attention to improving their own quality; companies do not pay attention to improving the quality of skilled workers, and they will be in danger of being eliminated in free market competition; high-quality Skilled workers are the precious wealth of enterprises and society, and the basic core of representatives of advanced productivity ${ }^{[2]}$. Therefore, through vocational skills training to improve the quality of skilled workers, training will naturally become an important starting point for enterprises to improve their competitiveness. Therefore, improving the effectiveness of training has also become one of the important links for China to enter high-quality development.

\section{Survey object}

Based on the manufacturing industry in Hubei Province, this paper summarizes the problems existing in the vocational training process of manufacturing skilled workers in Hubei Province through the analysis of effective data and field investigations and proposes corresponding countermeasures.

According to the skill level of the surveyed skilled workers, $10 \%$ are senior technicians, $22.5 \%$ are technicians, $15.5 \%$ are senior workers, $18.5 \%$ are intermediate workers, $14.0 \%$ are junior workers, and $19.5 \%$ are non-professional workers. Distribution of samples It is more uniform, which helps to better reflect the demands of skilled workers at all levels.From the age of the surveyed skilled workers, $24.4 \%$ are skilled workers under $30,49.3 \%$ are $30-40$ years old, $23.9 \%$ are $40-50$ years old, and those over 50 years old $2.5 \%$. The skilled workers surveyed are mainly young and middle-aged skilled workers.Judging from the relevant certificates held by the surveyed skilled workers, $0.5 \%$ have no certificate, $32.5 \%$ have a professional qualification certificate, $26 \%$ have a professional skill level certificate, $16 \%$ have a special occupational ability certificate, and special operations Operating certificates account for $22 \%$, and training qualification certificates account for $12 \%$. Vocational skills competition certificates accounted for $7 \%$.Judging 
from the educational background of the surveyed skilled workers, the number of undergraduate and higher vocational workers is basically the same. The two types of skilled workers together accounted for $62.5 \%$ of the survey ratio, and middle-level workers accounted for $20.5 \%$. Because the questionnaire did not include junior high school and The following qualifications, so most of the other qualifications here can be considered as those below junior high school.

\section{The Status Quo of Skill Training for Manufacturing Skilled Workers in Hubei Province}

This report sorts out and analyzes the status quo of skilled worker training in terms of the organization, methods, conditions, needs, and effects of skill training.

\subsection{The enterprises of skills training ensure that there are basically arrangements}

Table1. Training organization issues

\begin{tabular}{|c|c|c|}
\hline \multicolumn{3}{|c|}{ Professional skills improvement related data } \\
\hline content & \begin{tabular}{|c|} 
Options \\
\end{tabular} & proportion \\
\hline \multirow{4}{*}{$\begin{array}{l}\text { Vocational skill improvement } \\
\text { system guarantee }\end{array}$} & Full-time staff for vocational skills training & $50.0 \%$ \\
\hline & With vocational skills training center & $62.5 \%$ \\
\hline & Set up a skill improvement leadership group & $62.5 \%$ \\
\hline & Establish corporate leadership & $87.5 \%$ \\
\hline \multirow{4}{*}{$\begin{array}{l}\text { The relevant system for improving } \\
\text { vocational skills formulated by the } \\
\text { company }\end{array}$} & Vocational skill improvement training system & $62.50 \%$ \\
\hline & Vocational skill improvement evaluation system & $62.50 \%$ \\
\hline & Vocational skill improvement incentive system & $75 \%$ \\
\hline & 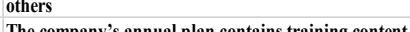 & $37.50 \%$ \\
\hline \multirow{3}{*}{$\begin{array}{c}\text { Annual plan for vocational } \\
\text { training of enterprise technical } \\
\text { workers }\end{array}$} & $\begin{array}{l}\text { The company's annual plan contains training content } \\
\text { Never made }\end{array}$ & $\begin{array}{r}37.50 \% \\
0.00 \%\end{array}$ \\
\hline & Partial annual formulation & $25 \%$ \\
\hline & Formulated annually & $75 \%$ \\
\hline
\end{tabular}

Vocational skill training centers or similar institutions accounted for $62.5 \%$, of which state-owned enterprises accounted for $80 \%$. From this result, most state-owned enterprises in Hubei Province have the conditions and ability to set up vocational skills training centers, while private enterprises, especially small private enterprises, find it difficult to set up their own training institutions or organizations.

From the perspective of establishing vocational skills training full-time personnel, $50 \%$ have full-time personnel to guide skilled workers to conduct vocational and technical training, while $80 \%$ of enterprises that have established vocational skills training centers or similar institutions have full-time personnel. Trainers. Obviously, the vocational skills training center has a high degree of accompany with full-time training personnel.87.5\% of the companies identified leaders as supervisors, indicating that companies attach importance to the vocational skills training of skilled workers and want to improve the vocational ability and professional quality of skilled workers through effective system measures.

Planning is a relatively comprehensive and long-term implementation of vocational skills training and development plan formulated by an enterprise. It is a reflection and consideration of the overall, long-term, and fundamental issues in the future, and is a plan for designing a set of future actions. The plan is the goal of corporate training to be achieved in a certain period in the future and the way to achieve the training effect. Among the surveyed companies, $62.5 \%$ and $75 \%$ of the companies that have formulated plans and plans, $12.5 \%$ of companies that have not yet decided to formulate a plan, and 0 companies that have never made a plan.

According to regulations, $87.5 \%$ of companies have training leadership organizations, $75 \%$ of companies have annual training plans, $62.5 \%$ of companies have training systems for vocational skills improvement, and $50 \%$ of companies have full-time skill training personnel. However, there are still private enterprises and a small number of state-owned enterprises that have not set up their own training centers, nor have they trained their own full-time personnel. All enterprises have formulated annual plans for vocational skills training, but some enterprises have only plans but no plans.

\subsection{Methods of skill training}

"Daily work accumulation" accounted for $31.5 \%$, and the number of people who passed technical training on the job accounted for $50 \%$. Comparing the skill improvement of the "teacher with apprentice" method, it shows that skills training and the traditional "teacher with apprentice" model are the most important of enterprises Ways to improve skills. $23 \%$ of skilled workers improve their skills through personal self-study. It is still necessary to pay attention to the fact that the scale of "teacher and apprentice" in a single enterprise has reached more than $2 / 3$, and there are also enterprises without a "teacher and apprentice" model. The "teacher leads apprentice" model has huge differences.

The effect of job skill training is the result of the combined effects of all related factors, and it is also the goal of training. Choosing an appropriate method and analyzing the reasons that affect the effect is an important reference for organizing job skills training in the future. Table2. Training effectiveness

\begin{tabular}{|c|c|c|}
\hline \multicolumn{3}{|c|}{ Professional skills improvement related data } \\
\hline content & Options & proportion \\
\hline \multirow{7}{*}{$\begin{array}{l}\text { How to improve skilled } \\
\text { workers in this unit }\end{array}$} & Teacher and apprentice & $52.50 \%$ \\
\hline & Job Training & $50 \%$ \\
\hline & Skill competition & $19.50 \%$ \\
\hline & Self-study & $23 \%$ \\
\hline & Skills Exchange Lecture & $12.50 \%$ \\
\hline & Daily work accumulation & $31.50 \%$ \\
\hline & others & $4 \%$ \\
\hline \multirow{7}{*}{$\begin{array}{l}\text { Skilled workers think that } \\
\text { skill training is effective }\end{array}$} & Internal communication of the training class & $45.45 \%$ \\
\hline & Teaching by corporate practice instructor & $33.84 \%$ \\
\hline & Professor teaching mode & $9.60 \%$ \\
\hline & Taught by industry experts & $18.18 \%$ \\
\hline & Learn via internet & $11.62 \%$ \\
\hline & Actual post operation & $55.56 \%$ \\
\hline & others & $1.01 \%$ \\
\hline \multirow{4}{*}{ Training needs } & Satisfied & $45 \%$ \\
\hline & basically satisfied & $29 \%$ \\
\hline & partially satisfied & $18 \%$ \\
\hline & not satisfied & $8 \%$ \\
\hline
\end{tabular}

$55.56 \%$ of skilled workers believe that the best way of skill training is actual job operation, and as the main method of training, internal communication in training classes, lectures by corporate practice instructors, lectures by teachers in colleges and universities, lectures by industry experts, and Internet lectures are all The results of theoretical teaching are lower than actual post operations. This result shows that the best training effect may be practice-oriented rather than theoretical teaching. It fully illustrates the degree of recognition of "practiceoriented" training by skilled workers.

According to the survey data, the training of skilled workers presents the characteristics of multiple channels and types, which also reflects the diversification of 
vocational training methods for skilled workers. $33.84 \%$ of skilled workers use corporate practice instructors to teach, and $11.62 \%$ of skilled workers use "Internet Participate in training in the form of "+", and today with the rapid development of the Internet, the "Internet + " model of online training is not highly recognized among skilled workers, reflecting the weak learning ability of skilled workers, the disconnection of teaching materials from practice, and skills training Emphasis on issues such as theoreticalization.

\subsection{The cost of skills training is mainly borne by the business owner}

The main sources of funds for the promotion of vocational skills of skilled workers may include the government, enterprises, society and skilled workers. From the survey data on enterprises, the proportion of enterprises using employee education funds to organize training is the highest, reaching $75 \%$; another $50 \%$ of enterprises have set up special funds for training, and $37.5 \%$ of enterprises allocate special funds as needed. The proportion of enterprises that received government awards and subsidies was $50 \%$, and the proportion of enterprises that paid personal contributions was $12.5 \%$, and no enterprises received social donations.

Table3. Impact of funds on skills upgrading

\begin{tabular}{|c|c|c|}
\hline \multicolumn{3}{|c|}{ Professional skills improvement related data } \\
\hline content & $\begin{array}{l}\text { Options } \\
\end{array}$ & proportion \\
\hline \multirow{6}{*}{$\begin{array}{l}\text { Sources of Skills } \\
\text { Upgrading Funds }\end{array}$} & Government incentives or subsidies & $50.00 \%$ \\
\hline & Enterprise employee education funds & $75 \%$ \\
\hline & Enterprises set up special funds by themselves & $50.00 \%$ \\
\hline & Enterprise special allocation & $38 \%$ \\
\hline & Social donation & $0.00 \%$ \\
\hline & Workers' individual contributions & $12.50 \%$ \\
\hline \multirow{5}{*}{$\begin{array}{l}\text { Attitude of skilled } \\
\text { workers to bear the cost }\end{array}$} & all & $10.50 \%$ \\
\hline & 75\% & $7.50 \%$ \\
\hline & $\mathbf{5 0 \%}$ & $18.50 \%$ \\
\hline & $25 \%$ & $47.00 \%$ \\
\hline & none & $16.50 \%$ \\
\hline
\end{tabular}

It can be seen that only $16.5 \%$ of skilled workers are unwilling to bear any training costs, and the proportion of skilled workers willing to bear about $25 \%$ and more than $50 \%$ of the training costs reaches $47 \%$ and $36.5 \%$. The data reflects that skilled workers recognize that vocational skill improvement training has positive value for themselves and are willing to bear the cost; but the value to the enterprise is greater, so more than $60 \%$ of skilled workers are only willing to bear a small part of the cost or not to bear the cost.

\subsection{The evaluation of the effectiveness of skills training is optimistic}

Table4. training results

\begin{tabular}{|c|c|c|c|}
\hline \multicolumn{4}{|c|}{ Professional skills improvement related data } \\
\hline content & Options & Manager proportion & skilled worker proportion \\
\hline \multirow{5}{*}{$\begin{array}{l}\text { training } \\
\text { results }\end{array}$} & best & $22.45 \%$ & $38.31 \%$ \\
\hline & better & $51.02 \%$ & $34.33 \%$ \\
\hline & good & $26.53 \%$ & $22.39 \%$ \\
\hline & bad & $0 \%$ & $2.49 \%$ \\
\hline & Worst & $0 \%$ & $2 \%$ \\
\hline
\end{tabular}

According to the survey, technical workers think that the training effect is "good", accounting for $38.31 \%$, while the manager's evaluation is "good" accounting for the majority, accounting for $51.02 \%$; skilled workers have a "good" effect on the training effect The proportion of skilled workers is $34.33 \%$, the average is $22.39 \%$, and the proportion of poor and poor skilled workers is $2.49 \%$. In comparison, managers hold a "good" view of the training effect at $22.45 \%$. What is most noticeable is that managers have no negative comments on training effects, while technical workers have nearly $5 \%$ negative comments.

In summary, training is effective if there is a general consensus on improving Hubei's manufacturing industry in the enterprise market. The above data is obviously reflected in the choice of theory and practice. Skilled workers pay more attention to the improvement of practical ability. "Practice orientation" should become an important consideration in the choice of training methods. It should not only be guided by theory, but also should pay attention to practical operations. However, only $11.6 \%$ of skilled workers used the "Internet +" method to participate in training, which is obviously in contradiction with the trend of changes in learning methods brought about by technological development, reflecting the lack of independent learning ability of skilled workers, insufficient supply of electronic textbooks, and practice. Disjointed, unsatisfied learning conditions and many other reasons. In the survey, a skilled worker hopes to "produce some video teaching materials that are the same or similar to the work situation for training" as an example.

Compared with the training attitude mentioned in the previous article, they are also actively participating or supporting, but we still need to note that the prerequisite for participating in training is still the way and proportion of training costs. Therefore, once high-quality training is accompanied Because of the high fees, both enterprises and skilled workers should be reluctant to invest, but the results of high-quality training not only improve the overall quality of the country's skilled workers, but also improve the overall quality of the enterprise, but also for individual industrial workers. However, this change in thinking has not yet taken shape.

\section{Problems in the Skill Training of Manufacturing Skilled Workers}

Regarding the main problems in the vocational skill improvement training of skilled workers, six of the thirteen options are required to be selected. The results of the top six options are shown in TABLE 5.

Insufficient training continuity is the biggest problem, indicating that the training plan is not strong, the system is not enough, and the training effect lacks continuous influence. It corresponds to the training pertinence which is one of the main factors affecting the training effect; the training pertinence is considered to be the impact The most important reason for the training effect, but from the perspective of the problem, continuity goes beyond pertinence, indicating that there should be a connection between one training and continuous training, and the long-term effect is more important than the short-term effect; teachers, teaching materials, funds, and bases are all training The external basic conditions for effective development show that the external conditions of training have not met the expectations of skilled workers from the perspective of the problem. 
Table5. The main problems in skills training

\begin{tabular}{|c|c|c|}
\hline & Professional skills improvement related data & \\
\hline \multirow{14}{*}{$\begin{array}{l}\text { The main problems in } \\
\text { skills training }\end{array}$} & $\begin{array}{l}\text { Options } \\
\end{array}$ & proportion \\
\hline & Not very targeted & $71.60 \%$ \\
\hline & Insufficient training continuity & $\mathbf{7 8 . 7 0 \%}$ \\
\hline & Lack of teachers & $72.30 \%$ \\
\hline & Lack of training materials & $65.20 \%$ \\
\hline & Insufficient funding & $60.70 \%$ \\
\hline & Insufficient training base & $60.70 \%$ \\
\hline & The training form is not rich & $60.03 \%$ \\
\hline & Insufficient training time & $57.48 \%$ \\
\hline & The government does not pay enough attentif & $29.68 \%$ \\
\hline & Enterprise not paying enough attention & $16.81 \%$ \\
\hline & Not enough personal attention & $14.87 \%$ \\
\hline & Training has little to do with personal interes & $15.48 \%$ \\
\hline & others & $3.22 \%$ \\
\hline
\end{tabular}

Strengthening the construction of the teaching staff, attaching importance to the construction of training materials and training bases, and ensuring sufficient training funds are matters that should be focused on in future work. There are fewer training forms and insufficient training time. The selection ratio has reached $60 \%$ and $57.4 \%$, ranking seventh and eighth, indicating that training should be carried out in as many ways as possible and sufficient time guarantee. Skilled workers did not pay special attention to the relationship between training and benefits. Only $15.5 \%$ of them took it as a problem. On the one hand, it shows that training effects are more important than short-term benefits. On the other hand, it shows that benefits are not the main consideration in training expectations.

\section{Skills training improvement measures for skilled workers}

\subsection{Pay attention to the formulation of skills training plans, and confirm or guide them}

Using big data, skills training plans can be formulated individually or integrated into other comprehensive plans. Through skills training planning, the continuity of skills training is guaranteed, and it is determined in legal form or guided by administrative regulations.

In the process of formulating skills training plans, attention should be paid to the following matters: (1) The main body of the preparation, approval and publication of the plan; (2) The preparation period of the plan; (3) The key industries and positions for skills training; (4) The organization of skills training Implementation; (5) Modification and abolition of the plan.

Skills training planning mainly considers government planning, industry planning and enterprise planning. The government planning proposal is led by the human resources department or the labor union, and the relevant departments are jointly prepared and incorporated into the legislation. The provincial government plan is an important guiding document for skills training in Hubei Province and is announced by the lead unit after approval by the provincial government; the plan is 5 The year is a cycle, corresponding to the national economic and social development plan. Special attention is paid to the training arrangements for the ten key industries in our province. There are both mandatory requirements and guiding arrangements. Lower-level government plans need to be based on higher-level government plans and combined with local characteristics; industry plans are based on higher-level and same-level government plans, and are prepared by industry associations in accordance with industry characteristics; enterprise plans are based on local government plans and industry plans. And combined with enterprise characteristics.

\subsection{Focus on cultivating "dual-professional" teachers and guarantee them through laws}

Taking the cooperation between vocational colleges and powerful enterprises as the basic method, strengthen the construction of skill training teachers, allocate special funds, and increase remuneration to provide a good external environment for the growth of "double-qualified" teachers. And allow to enjoy tax exemption within a certain limit, through relevant legal system amendments, thereby increasing the size of the teaching staff. (1) Government departments should provide institutional support for the thorough development of professional and technical talents, encourage professional and technical talents to declare skill levels, and encourage skilled talents to declare professional and technical titles. (2) Guide vocational colleges and enterprises to engage in mutual employment, through college teachers to enter the enterprise, and skilled talents will step onto the stage to provide practical conditions for cultivating "doublequalified" teachers. The practice of hiring winners of skill competitions by vocational schools in Yichang City is worth promoting. (3) Give full play to the special role of high-skilled leading talents, and organize high-skilled leading talents lecturers and advisory groups according to the industry to directly participate in the construction of the "dual teacher" faculty.

\subsection{Fully consider the practicality of training}

First, deal with the relationship between theory and practice in skill training based on the principle of "practice-oriented", make full use of the big data platform, aim at the needs of skilled workers, serve the practice, and endow no actual needs. That is to say, theoretical teaching should serve the needs of practice, with the basic model of "practice in learning and learning in practice". Second, increase the proportion of practical teaching in the training process and moderately compress the content of theoretical teaching. Third, encourage simulation training and strengthen the unity of training and practice. Fourth, carry out a pilot program of training both theoretical and practical teachers in the same class. Through the collaboration of the two teachers, the integration of theory and practice can be realized. If the pilot is successful, it can be gradually promoted.

\subsection{Actively promote and compile training instruction materials for legalization}

A special working group is organized by the leading unit of government planning and preparation, and several groups are set up according to the industry, responsible for the recommendation, compilation and organization of skills training materials. The responsibilities of various industry associations should have this responsibility, and 
should be confirmed by law, make full use of the big data platform, and eliminate outdated theories and data to ensure that the teaching materials are scientific and novel, and are more suitable for skilled workers. Learning and use (1) Collect information on existing training materials in a comprehensive way, and recommend authoritative training materials for selection by training units on the basis of screening. (2) According to the needs of skill training in our province, formulate a plan for the compilation of training materials in our province on an annual basis, and organize or select experts to implement the compilation of teaching materials. (3) Require textbook writers to update the content of electronic training textbooks in a timely manner and provide convenient channels for users to obtain textbooks. (4) Encourage vocational colleges, enterprises and other units to independently prepare skills training textbooks and report them. If approved and listed in the recommended textbook catalog, the compiler will be given certain rewards and financial support for updating the content of the textbooks.

\subsection{Effective and clear use of government awards to supplement funds}

For skills training rewards and subsidies with government background, they should be used fully and effectively. Regarding the disbursement of funds, the provinces should formulate measures to clarify those that meet the conditions, rather than randomly handling them. The data platform can also be used for real-time tracking, and data accounting for the use of rewards and subsidy funds. For companies that can really improve most of the rewards and subsidies funds, they should be supported and increased investment. These should be institutionalized and confirmed.(1) Actively publicize the government's policy on the use of skills training bonus funds, so that more enterprises and skilled workers are aware of and actively apply for and obtain the funds. (2) Appropriately relax the requirements on the skill training process, pay more attention to the inspection of training results, and ensure the fair distribution of bonus funds. (3) Increase financial support for enterprise skills training, strengthen the supervision of the use of government bonus funds by enterprises, and ensure the efficiency of the use of bonus funds.

\subsection{Advocate the use of "Internet +"}

In the wave of the era of big data, skill training for skilled workers is facing informatization, standardization, and intelligence. The Internet + training model will be an inevitable choice. (1) With the help of the training and learning system, people can participate in training to form full-staff training; (2) Mobile learning is realized with the support of the Internet, breaking through the limitations of time and space, and making use of the fragmented time of skilled workers; (3) Taking "training knowledge points" as a unit, gradually build training resource packages for different positions, and adopt the "credit bank" approach to ensure the continuity of training.

\section{Conclusions}

Through legal thinking, trade union organizations can use big data to help type enterprises solve the system construction, encourage enterprises to use big data to optimize their own training methods, not only through theoretical methods such as face-to-face lectures and online courses, but also practice-oriented, new The apprenticeship model and simulation training model should be introduced, and the digitalization of law and big data should be used to increase investment and subsidies to specific enterprises to resolve outstanding employment contradictions; through big data scientific calculations, enterprises should consider training for them in the longer term. Long-term value, combined with effective punitive and incentive mechanisms, can effectively solve the thinking problem of skilled worker training.

\section{Acknowledgment}

First, I would like to thank the labor union in Hubei Province for their support and manufacturing companies in various regions for their feedback on the questionnaire. Secondly, Under the meticulous guidance of Professor Wang, the paper was completed and written, time was tight and tasks were arduous. Finally, I would also like to thank the teachers and classmates of the research team for their help, and spent a lot of time helping with questionnaire statistics and data processing. Thank you for your six months of working together and staying up late.

\section{References}

1. Meng Xiaofeng, Cixiang. Big Data Management: Concept, Technology and Challenges[J]. Computer Research and Development, 2013, 50(001):146-169.

2. Cui Xiaojing. Investigation on the status quo of quality education for industrial workers in Beijing and its countermeasures[D].

3. Xinhua News Agency. The Central Committee of the Communist Party of China and the State Council issued the "Industrial Worker Team Building Reform Plan in the New Era".

4. Vocational Education Research[M]. Anhui People's Publishing House, He Xiaogang, 2006.

5. Wang Dong, Zhang Gang. On the role of trade unions in building harmonious labor relations in enterprises[J]. Chinese Business (Part 2)(03):282.

6. Li Ran. Looking at the development of training in the era of big data from the perspective of training productization[J]. World of Labor and Social Security, 2015, 000(011):21. 